\title{
Play your hand wisely
}

\author{
Thomas S. Maxey, MD
}

From the Sanger Congenital Heart Center, Levine Children's Hospital, Atrium Health, Charlotte, NC.

Disclosures: Author has nothing to disclose with regard to commercial support.

Received for publication Nov 12, 2018; accepted for publication Nov 12, 2018; available ahead of print Dec 24, 2018.

Address for reprints: Thomas S. Maxey, MD, Sanger Congenital Heart Center, Levine Children's Hospital, 1001

Blythe Blvd, Suite 200, Charlotte, NC 28203 (E-mail: Thomas.maxey@atriumhealth.org).

J Thorac Cardiovasc Surg 2019;157:1128-9

$0022-5223 / \$ 36.00$

Copyright (c) 2018 by The American Association for Thoracic Surgery

https://doi.org/10.1016/j.jtcvs.2018.11.054

Mery and colleagues ${ }^{1}$ have nicely described their singlecenter analysis of surgically repaired partial and transitional (P/T) atrioventricular septal defects (AVSDs). Their article in this issue of the Journal adds another piece to the puzzle regarding expectations and ideal timing of P/T AVSD repair. Not surprising, Mery's group demonstrates outstanding survival through 22 years with 265 patients. The subtleties of their analysis, however, are in the details of reintervention. The 10-year reintervention rate for left atrioventricular valve (LAVV) pathology is nearly $20 \%$, and left ventricular outflow tract (LVOT) obstruction is $7 \%$.

Despite the seemingly straightforward surgical repair of $\mathrm{P} / \mathrm{T}$ AVSD, the incidence of late LAVV regurgitation or LVOT obstruction is significant compared with that of complete AVSD. ${ }^{2}$ This finding is related to the attached nature of the bridging leaflets to the crest of the ventricular septum, which further exaggerates the elongated narrowing of the LVOT. As Mery and colleagues ${ }^{1}$ point out, the ideal time for surgical repair varies greatly in the literature: Minnich and coworkers ${ }^{3}$ concluded that children should undergo repair younger than 4 years of age because of the increased incidence of LAVV regurgitation in children older than 4 years. Devlin and colleagues ${ }^{4}$ demonstrated no increased incidence of reintervention in younger children and recommended repair before 2 years of age. The multicenter study of Burrato and associates ${ }^{5}$ recommended that surgery be deferred until later in childhood, whereas the analysis of Aubert and colleagues ${ }^{6}$ suggested that an even later age at operation may be beneficial.

The difficult reality is that a reasonable percentage of patients with $\mathrm{P} / \mathrm{T}$ AVSD present in infancy with moderate to severe LAVV incompetence and at least some signs of congestive heart failure. In this cohort, $73 \%$ or $27.5 \%$ of patients, respectively, fall into these categories. It is this specific population for which many conflicting opinions regarding timing of repair occur. The analysis of Mery and colleagues ${ }^{1}$ demonstrates that patients who underwent repair during infancy were more likely to require some form of reintervention (nearly $24 \%$ at 10 years, compared

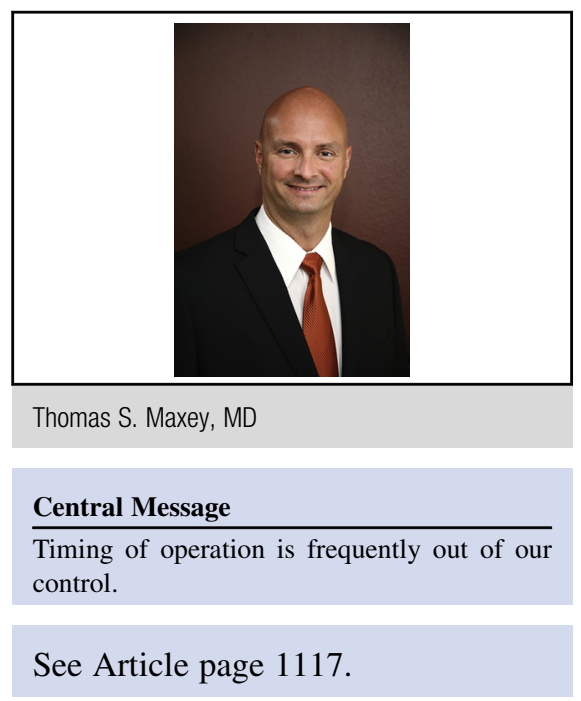

with $13 \%, 5 \%$, and $0 \%$ reintervention rates for toddlers, children, and adults, respectively). The reader should be cautious in interpreting these data, however, and not wait for a symptomatic infant to become older with the sense that waiting will lead to lower reintervention rates. As Mery and colleagues ${ }^{1}$ state, this finding is likely a marker of more severe disease than the actual timing or performance of the repair. I strongly agree with their practice, however, that surgery should be offered to infants with moderate to severe atrioventricular valve regurgitation or signs of heart failure.

For symptom-free patients, however, Mery and colleagues ${ }^{1}$ suggest that a repair "later in life" may be reasonable. Interestingly, most surgeons have little input as to when the relatively symptom-free 2 -year-old with a partial canal is referred for surgery. I personally believe that delaying the operation to 4 or 5 years of age leads to further annular dilation, making the repair potentially more difficult.

As Mery and colleagues ${ }^{1}$ state, inherent in this study is selection bias. Patients underwent surgery when the cardiologist and surgeon believed that the child would experience the best outcome, and therefore, all age groups cannot be considered equal. Patients for whom surgery is delayed until 3 years of age, or 18 years of age, are a different population than those undergoing surgery at 3 months of age and are not randomly selected. Physiologic and anatomic differences influence decisions, making it difficult to compare the outcome of the 3 age groups on equal ground. 
I commend Mery and colleagues ${ }^{1}$ on their outstanding results. They conclude that although the risk of mortality was minimal, reoperations for LAVV and LVOT were significant, with repair during infancy being an important risk factor for reoperation. This finding is sound and supported by their data. The unfortunate reality is that unless a child is in the hospital in heart failure, we will still experience vast differences in opinion regarding the ideal time to perform repair in children with P/T AVSDs. It goes without saying that having a great hand of cards increases the chance of winning but really does not guarantee a victory. Similarly, having a less than desirable hand does not necessarily translate to losing. As a surgeon, strong clinical judgment and appropriate patient counseling regarding expectations are the best way to play the hand that you are dealt.

\section{References}

1. Mery CM, Zea-Vera R, Chacon-Portillo MA, Zhang W, Binder MS, Kyle WB, et al. Contemporary results after repair of partial and transitional atrioventricular septal defects. J Thorac Cardiovasc Surg. 2019;157:1117-27.

2. Najm HK, Williams WG, Chuaratanaphong S, Watzka SB, Coles JG Freedom RM. Primum atrial septal defect in children: early results, risk factors, and freedom from reoperation. Ann Thorac Surg. 1998;66:829-35.

3. Minich LL, Atz AM, Colan SD, Sleeper LA, Mital S, Jaggers J, et al; Pediatric Heart Network Investigators. Partial and transitional atrioventricular septal defect outcomes. Ann Thorac Surg. 2010;89:530-6.

4. Devlin PJ, Backer CL, Eltayeb O, Mongé MC, Hauck AL, Costello JM. Repair of partial atrioventricular septal defect: age and outcomes. Ann Thorac Surg. 2010; 89:530-6.

5. Buratto E, Daley M, Ye XT, Radford DJ, Alphonso N, Brizard CP, et al. Propensity score matched analysis or partial atrioventricular septal defect repair in infancy. Heart Br Card Soc. 2018;104:1014-8.

6. Aubert S, Henaine R, Raisky O, Chavanis N, Robin J, Ecochard R, et al. Atypical forms of isolated partial atrioventricular septal defect increase the risk of initial valve replacement and reoperation. Eur J Cardiothorac Surg. 2005;28:223-8. 